\title{
Correlation between penile cavernosal artery blood flow and retinal vascular findings in arteriogenic erectile dysfunction
}

This article was published in the following Dove Press journal:

Clinical Ophthalmology

15 September 2010

Number of times this article has been viewed

\author{
Ahmed M Emarah' \\ Shawky M El-Haggar ${ }^{2}$ \\ Ihab A Osman ${ }^{2}$ \\ Abdel Wahab S Khafagy ${ }^{2}$ \\ 'Departments of Ophthalmology, \\ ${ }^{2}$ Andrology and Sexology, Cairo \\ University Hospital, Egypt
}

Objectives: Arteriogenic erectile dysfunction (ED) is a target organ disease of atherosclerosis, and therefore might be a predictor of systemic atherosclerosis. Being systemic, it might be possible to evaluate the extent of atherosclerosis from retinal vascular findings. We investigated the possible correlation between penile cavernosal artery blood flow and retinal vascular findings in patients with arteriogenic ED.

Patients and methods: Sixty patients with ED were divided according to the peak systolic velocity (PSV) in their penile cavernosal arteries into two groups; Group A included 30 patients with PSV less than $25 \mathrm{~cm} / \mathrm{sec}$, and Group B included 30 patients with PSV more than $35 \mathrm{~cm} / \mathrm{sec}$. Blood flow in the penile cavernosal artery was measured with color Doppler ultrasonography. All patients were assessed by ocular fundus examination under amydriatic conditions to evaluate retinal vascular atherosclerotic changes using Hyman's classification.

Results: Evidence of retinal vascular atherosclerotic changes was found in 19 patients $(63.3 \%)$ in Group A and in 10 patients (33.3\%) in Group B.

Conclusions: Our study confirms the possibility of predicting penile arterial vascular status in patients with ED from their retinal vascular findings by using amydriatic simple, practical funduscopy.

Keywords: erectile dysfunction, atherosclerosis, retinal vascular atherosclerosis

\section{Introduction}

Erectile dysfunction (ED) is a prevalent condition that affects more than 150 million men worldwide, and is predicted to double within the next 20 years. ${ }^{1}$ Although ED was previously considered to be primarily psychogenic, recent research elucidating the physiology of penile erection, as well as the pathogenesis of ED shows accumulating evidence that ED should be considered as a vascular disorder. ${ }^{2}$

Atherosclerosis and ED not only share common risk factors, including dyslipidemia and cigarette smoking, but also show obvious coassociation with various cardiovascular and systemic vascular diseases, including coronary artery disease, hypertension, diabetes mellitus (DM), and peripheral and cerebrovascular diseases. ${ }^{3-5}$ Additionally, arteriogenic ED is identified as a marker for silent vascular disease and a predictor of systemic atherosclerosis. ${ }^{6-11}$

Atherosclerosis is a systemic disorder that uniformly affects the vascular system, even though clinical manifestations rarely appear simultaneously in different vascular beds in the same patient due to the different sizes of the arteries supplying different organs. In addition, endothelial dysfunction is associated with impaired release and activity of nitric oxide. ${ }^{12,13}$
Correspondence: Ahmed M Emarah

Cairo University, 6 I-Hegaz St,

Heliopolis, Cairo, Egypt II 34

Tel +20224550300

Fax +2012223551

Email emarahjr@gmail.com 
Retinal blood vessels are one of the most superficial branches of the vascular tree, and pathological changes in these vessels can be easily seen and recorded by funduscopy, which affords a unique opportunity for noninvasive assessment of the systemic microcirculation in large populations. ${ }^{14-16}$ Retinal microvascular abnormalities, such as retinal arteriolar narrowing and retinopathy, have been associated with systemic vascular disorders, including hypertension, metabolic syndrome, Type $2 \mathrm{DM}$, and cardiovascular diseases, suggesting it is a marker of atherosclerosis. ${ }^{17-20}$

Ocular funduscopy allows direct visualization of the retinal vasculature, and accordingly can be used routinely as a diagnostic tool for atherosclerosis, not only by ophthalmologists but also by primary care physicians. ${ }^{21}$

We investigated the possible correlation between penile cavernosal artery blood flow and retinal vascular findings in patients with arteriogenic ED.

\section{Patients and methods}

The research followed the tenets of the Declaration of Helsinki, and informed consent was obtained from patients to whom all details of the procedure were explained, with emphasis on the intended outcome. The research was approved by our institutional review board.

The study included 60 patients with ED recruited from the Andrology and Sexology Outpatient Clinic of the Cairo University Hospital. ED was defined as an inability to achieve or maintain an erection adequate for sexual intercourse for at least six months. ${ }^{22}$ All patients completed the validated Arabic translation of the International Index of Erectile Function (IIEF-5) questionnaire. ${ }^{23} \mathrm{ED}$ was diagnosed in patients having an IIEF-5 score of $<21 .{ }^{24}$

Exclusion criteria included diminished sexual desire, hypogonadism, hyperprolactinemia, Peyronie's disease, ED due to anatomical penile deformities, previous spinal cord injury, previous radical prostatectomy, any substance abuse disorders, a psychiatric history with or without medications, and DM (to avoid diabetes-specific retinopathies confounding our findings).

A medical, surgical, and psychosexual history was taken from all patients, and a detailed physical examination was performed. All patients were given an intracavernous injection of $20 \mu \mathrm{g}$ prostaglandin $\mathrm{E}_{1}$, and were then evaluated by penile dynamic duplex study using color ultrasound with a $7.5 \mathrm{mHz}$ linear array transducer having a color flow-mapping capability (Esaote Biomedical AU3, Italy).

The peak systolic velocity (PSV) of the penile cavernosal arteries was used to classify patients into two groups, ie, Group A which included 30 patients with PSV less than $25 \mathrm{~cm} / \mathrm{sec}$, and Group B which included 30 patients with PSV more than $35 \mathrm{~cm} / \mathrm{sec}$.

The same ophthalmologist carried out the fundus examination in all 60 patients to avoid interobserver variability. In addition, the ophthalmologist was masked as to the nature of the patient's andrological condition. Fundus examination was carried out using a 90 diopter indirect ophthalmoscopy lens, in conjunction with the slit lamp. This provided strong illumination, magnification, and stereoscopic view. Dilation with $1 \%$ tropicamide was only performed when media opacity or lack of patient cooperation prevented thorough and proper fundus examination. Fundus photography was only performed to document the findings in some cases, and was not used routinely. Evaluation of retinal vascular atherosclerotic changes was listed according to Hyman's classification..$^{25}$

Descriptive statistics (mean and standard deviation) were used for summarizing quantitative data, while percentages were used for qualitative data. Statistical analysis was performed using the chi-square test and the independent t-test. The 95\% confidence interval (CI) was calculated. Significance was set to $P<0.05$. All statistical calculations were done using computer program SPSS (Statistical Package for the Social Science: SPSS Inc, Chicago, IL).

\section{Results}

The present study was carried out in $60 \mathrm{ED}$ patients who were further divided into two groups according to their PSV determined by penile duplex study. Group A included 30 patients diagnosed as having arteriogenic ED (PSV less than $25 \mathrm{~cm} / \mathrm{sec}$ ), and Group B included 30 patients diagnosed as having nonarteriogenic ED (PSV more than $35 \mathrm{~cm} / \mathrm{sec}$ ).

The age (mean $+\mathrm{SD})$ of Group A patients was $50.83 \pm 8.98$ years, and for Group B patients was $46.07 \pm 11.11$ years. There was no statistical difference in age between the groups.

The clinical characteristics, hemodynamic values, and funduscopic findings for both groups are shown in the Table 1 .

On analyzing our data, highly significant differences were found in both groups for right and left PSV and IIEF-5 scores. The same differences for right and left PSV and IIEF-5 scores were found between smokers and nonsmokers, and between hypertensive and normotensive subjects.

Funduscopic findings showed that 32 ED patients had normal retinal vasculature, while 29 had abnormal retinal vascular findings (27 Grade I and two Grade II). Abnormal retinal vascular findings were detected in $63.3 \%(19 / 30)$ of patients with arteriogenic ED (Group A), while only 
Table I Data of the studied groups (mean \pm SD, range)

\begin{tabular}{|c|c|c|c|c|c|}
\hline & Total IIEF-5 & $\begin{array}{l}\text { Right PSV } \\
\text { (cm/sec) }\end{array}$ & $\begin{array}{l}\text { Left PSV } \\
(\mathrm{cm} / \mathrm{sec})\end{array}$ & $\begin{array}{l}\text { Right EDV } \\
(\mathrm{cm} / \mathrm{sec})\end{array}$ & $\begin{array}{l}\text { Left EDV } \\
(\mathrm{cm} / \mathrm{sec})\end{array}$ \\
\hline Group A $(n=60)$ & $\begin{array}{l}6.7 \pm 1.82 \\
(3-11)\end{array}$ & $\begin{array}{l}19.1 \pm 3.39 \\
(12.0-24.0)\end{array}$ & $\begin{array}{l}18.57 \pm 3.88 \\
(12.0-24.0)\end{array}$ & $\begin{array}{l}8.43 \pm 5.1 \\
(I-24)\end{array}$ & $\begin{array}{l}8.87 \pm 5.55 \\
(1.0-29.0)\end{array}$ \\
\hline Group B $(n=40)$ & $\begin{array}{l}10.73 \pm 2.84^{*} \\
(6.0-18.0)\end{array}$ & $\begin{array}{l}48.57 \pm 10.98^{*} \\
(36.0-76.0)\end{array}$ & $\begin{array}{l}49.83 \pm 11.37^{*} \\
(36.0-76.0)\end{array}$ & $\begin{array}{l}3.77 \pm 1.83^{*} \\
(1.0-7.0)\end{array}$ & $\begin{array}{l}3.3 \pm 2.1^{*} \\
(1.0-8.0)\end{array}$ \\
\hline \multicolumn{6}{|l|}{ Hypertensives } \\
\hline Group A $(n=22)$ & $6.36 \pm 1.03$ & $17.36 \pm 1.29$ & $15.82 \pm 2.44$ & $3.18 \pm 1.78$ & $2.18 \pm 1.6$ \\
\hline Group B $(n=8)$ & $10.83 \pm\left. 4.3\right|^{*}$ & $38.67 \pm 2.16^{*}$ & $42.67 \pm 6.53^{*}$ & $5.67 \pm 1.2^{*}$ & $7.0 \pm 2.37^{*}$ \\
\hline \multicolumn{6}{|l|}{ Normotensives } \\
\hline Group A $(n=38)$ & $6.89 \pm 2.16$ & $20.1 \pm 3.83$ & $20.16 \pm 3.7$ & $9.13 \pm 5.4$ & $9.33 \pm 6.04$ \\
\hline Group B $(n=23)$ & $|0.7| \pm 2.48^{*}$ & $51.04 \pm 10.9^{*}$ & $38.67 \pm 11.7^{*}$ & $4.11 \pm 1.82^{*}$ & $3.95 \pm 2.1^{*}$ \\
\hline \multicolumn{6}{|l|}{ Smokers } \\
\hline Group A $(n=28)$ & $6.86 \pm 2.14$ & $18.43 \pm 2.56$ & $17.64 \pm 3.48$ & $7.27 \pm 3.07$ & $7.82 \pm 3.06$ \\
\hline Group B $(n=14)$ & $10.9 \mid \pm 2.17^{*}$ & $45.45 \pm 8.12^{*}$ & $47.64 \pm 10.72^{*}$ & $3.29 \pm 1.98^{*}$ & $2.64 \pm 2.2^{*}$ \\
\hline \multicolumn{6}{|l|}{ Nonsmokers } \\
\hline Group A $(n=23)$ & $6.56 \pm 2.1$ & $19.69 \pm 3.2$ & $19.38 \pm 2.8$ & $9.1 \pm 5.9$ & $9.47 \pm 6.59$ \\
\hline Group B $(n=26)$ & $10.63 \pm 3.22^{*}$ & $50.37 \pm 12.2^{*}$ & $51.1 \pm 11.8^{*}$ & $4.19 \pm 1.1^{*}$ & $3.88 \pm 1.4^{*}$ \\
\hline \multicolumn{6}{|l|}{ Funduscopy } \\
\hline \multicolumn{6}{|l|}{ Group A } \\
\hline Normal $(n=22)$ & $6.55 \pm 2.02$ & $22.73 \pm 1.42$ & $22.82 \pm 1.33$ & $4.0 \pm 2.0$ & $4.1 \pm 2.1$ \\
\hline Affected $(n=38)$ & $6.79 \pm 1.75^{*}$ & $17.0 \pm 2.2^{*}$ & $16.1 \pm 2.42^{*}$ & $3.63 \pm 1.74^{*}$ & $2.8 \pm 2.0^{*}$ \\
\hline \multicolumn{6}{|l|}{ Group B } \\
\hline Normal $(n=28)$ & $11.2 \pm 3.13$ & $53.6 \pm 10.1$ & $54.8 \pm 10.8$ & $5.55 \pm 1.6^{*}$ & $6.0 \pm 1.9^{*}$ \\
\hline Affected $(n=12)$ & $9.80 \pm 1.93^{*}$ & $38.5 \pm 1.84^{*}$ & $39.9 \pm 2.4^{*}$ & $9.9 \pm 5.6^{*}$ & $10.3 \pm 6.2^{*}$ \\
\hline
\end{tabular}

Abbreviations: IIEF-5, score of the international index of erectile function questionnaire; PSV, peak systolic velocity; EDV, end diastolic velocity.

"Statistically significant.

$33.3 \%(10 / 30)$ of Group B patients showed retinal vascular abnormalities on funduscopic examination.

Among ED patients with normal retinal findings, the mean (SD) right and left PSV and IIEF-5 scores were 22.73 (1.42), 22.82 (1.33), and 6.55 (2.02) for Group A, and 53.6 (10.11), 54.8 (10.8), and 11.2 (3.14) for Group B patients, respectively. However, in ED patients with abnormal retinal findings, the mean (SD) right and left PSV and IIEF-5 scores were 17 (2.16), 17.11 (2.42), and 6.79 (1.75) for Group A, and 38.5 (1.84), 39.9 (2.42), and 9.8 (1.93) for Group B patients, respectively. Furthermore, a highly significant difference was detected in patients with normal and abnormal retinal findings within the same group for right and left PSV and IIEF-5 scores.

\section{Discussion}

ED is increasingly recognized as a neurovascular phenomenon which is particularly vulnerable to circulatory disturbances. Recent research provides accumulating evidence of the role of ED as a common precursor of systemic atherosclerosis, ${ }^{26}$ as well as highlighting its role in predicting cardiac and systemic vascular disorders. ${ }^{5-9,11}$ Atherosclerosis is a systemic disorder, however its clinical manifestations show an ordered progression, and recognition of atherosclerotic changes in one organ can predict the next organ likely to be affected. ${ }^{26}$ The retina provides a window of opportunity to study the human circulation. Retinal arterioles can be visualized easily and noninvasively, and have anatomical and physiological characteristics similar to those of the cerebral and coronary microcirculations, to the extent that the recognition of hypertensive retinopathy plays an important role in cardiovascular risk stratification of hypertensive patients. ${ }^{25}$

In the present study, abnormal retinal vascular findings were detected in $63.3 \%$ of arteriogenic ED patients, which is a significantly higher prevalence than the $33.3 \%$ of ED patients with normal penile cavernosal arterial blood flow. This suggests that the penile vascular bed represents a target organ for atherosclerosis, adding to the evidence of the close relationship between ED and systemic vascular diseases. Similarly, the retinal microvascular circulation represents another target for atherosclerotic abnormalities, including retinal arteriolar narrowing and retinopathy, which shows an association with many systemic vascular disorders, including hypertension, DM, and cardiovascular disease. ${ }^{17-20}$ In our study, the mean right and left PSV and IIEF-5 scores were significantly lower in arteriogenic ED patients with retinal involvement than those of the nonarteriogenic ED group $(P<0.01)$. 
Smoking is one of the main risk factors implicated in the pathogenesis of both ED and systemic atherosclerotic vascular disease. ${ }^{27}$ In our study, smokers represented $46.7 \%$ of arteriogenic ED patients compared with $36.7 \%$ of the nonarteriogenic group. In 2003, Kawanishi et al failed to find a significant effect of cigarette smoking on cavernosal or fundus artery findings, attributing this to the difficulty in measuring exposure to cigarette smoking. ${ }^{14}$ However, the right and left PSV and IIEF-5 scores of our patients were significantly different between smokers and nonsmokers $(P<0.01)$.

Similarly, our data revealed highly significant differences in right and left PSV and IIEF-5 scores between hypertensive and normotensive ED patients. This observation differs from that of Kawanishi et al who found that hypertension was not a significant factor for retinal findings or cavernosal arterial status, stating that all the hypertensive patients in their study had adequately controlled blood pressure. ${ }^{14}$

Although the various clinical classifications of retinal vascular findings remain controversial, funduscopic assessment of retinal vascular abnormalities is still the only clinical tool that can detect arteriolar abnormalities. ${ }^{28,29}$ In spite of the existence of several classifications of hypertensive retinopathy, their relevance to current clinical practice is still questionable. The major criticisms are that they do not enable the clinician to distinguish between low retinopathy grades and that these retinopathy grades failed to be closely correlated with the severity of hypertension. ${ }^{1,30-33}$ Hence we chose to use the Hyman's classification which clearly distinguishes between retinal vascular abnormalities on the basis of localized constriction, arteriolar stenosis or nicking, hemorrhage, exudates, and disk edema. ${ }^{25}$

Although we totally agree with studies showing that signs of hypertensive retinopathy can be reliably identified with a standardized examination of photographs of the fundus, we believe that these systems might introduce errors of their own because they are highly sophisticated methods that rely on highly specialized and adequately trained ophthalmologists. ${ }^{34,35}$ However, even if such software becomes widely available, it is expensive and therefore puts a burden on struggling economies. Hence our decision was to rely on readily available ophthalmic equipment that is more economical and serves as a simple, practical, acceptable, noninvasive screening tool for large populations, and can be used even by primary care physicians. Additionally, this method would be more economical in developing countries for investigating patients seeking medical advice for ED, where it would be unacceptable to involve them in expensive, time-consuming, and invasive investigations for screening purposes.

Our study suggests the possibility of correlating penile arterial vascular status in patients with ED with retinal vascular findings by using amydriatic funduscopy, which is a simple practical method.

Arteriogenic ED is a target organ disease of atherosclerosis that adds to the evidence of a close relationship between ED and cardiovascular diseases.

\section{Acknowledgment}

This article was presented by Professor Shawky El-Haggar at The International Society of Sexual Medicine Congress held in September 2006 in Cairo, Egypt.

\section{Disclosure}

The authors have no financial interest as consultants, reviewers, shareholders, or evaluators in any of the products mentioned. No financial grants from public or private organizations were received.

\section{References}

1. Meuleman EJ. Prevalence of erectile dysfunction: Need for treatment? Int J Impot Res. 2002;14 Suppl 1:S22-S28.

2. Shabsigh R, Anastasiadis AG. Erectile dysfunction. Annu Rev Med. 2003;54:153-168.

3. Bortolotti A, Parazzini F, Colli E, Landoni M. The epidemiology of erectile dysfunction and its risk factors. Int J Androl. 1997;20:323-334.

4. Feldman HA, Goldstein I, Hatzichristou DG, Krane RJ, McKinlay JB. Impotence and its medical and psychosocial correlates: Results of the Massachussetts Male Aging Study. J Urol. 1994;151:54-61.

5. Roumeguere T, Wespes E, Carpentier Y, Hoffmann P, Schulman CC. Erectile dysfunction is associated with a high prevalence of hyperlipidemia and coronary heart disease risk. Eur Urol. 2003;44:355-359.

6. Burchardt M, Burchardt T, Anastasiadis AG, et al. Erectile dysfunction is a marker for cardiovascular complications and psychological functioning in men with hypertension. Int J Impot Res. 2001;13:276-281.

7. El-Sakka A, Morsy A, Fagih B. Enhanced external counterpulsation in patients with coronary artery disease-associated erectile dysfunction. Part I: Effects of risk factors. J Sex Med. 2007;4:771-779.

8. Heruti RJ, Uri I, Arbel Y, Swartzon M, Galor S, Justo D. Erectile dysfunction severity might be associated with poor cardiovascular prognosis in diabetic men. J Sex Med. 2007;4:465-471.

9. Jackson G. Erectile dysfunction: A marker of silent coronary artery disease. Eur Heart J. 2006;27:2613-2614.

10. Kaya C, Uslu Z, Karaman I. Is endothelial function impaired in erectile dysfunction patients? Int J Impot Res. 2006;18:55-60.

11. Solomon H, Man JW, Jackson G. Erectile dysfunction and the cardiovascular patient: Endothelial dysfunction is the common denominator. Heart. 2003;89:251-253.

12. Bocchio M, Desideri G, Scarpelli P, et al. Endothelial cell activation in men with erectile dysfunction without cardiovascular risk factors and overt vascular damage. J Urol. 2004;171:1601-1604.

13. Cheitlin MD. Erectile dysfunction: The earliest sign of generalized vascular disease? J Am Coll Cardiol. 2004;43:185-186.

14. Kawanishi Y, Kimura K, Nakanishi R, Numata A, Taguchi H. Retinal vascular findings and penile cavernosal artery blood flow. BJU Int. 2003; 92:977-980. 
15. Wong TY, Klein R, Klein BE, Tielsch JM, Hubbard L, Nieto FJ. Retinal microvascular abnormalities and their relationship with hypertension, cardiovascular disease, and mortality. Surv Ophthalmol. 2001;46:59-80.

16. Wong TY, McIntosh R. Systemic associations of retinal microvascular signs: A review of recent population-based studies. Ophthalmic Physiol Opt. 2005;25:195-204.

17. Klein BE, Klein R, McBride PE, et al. Cardiovascular disease, mortality, and retinal microvascular characteristics in Type 1 diabetes: Wisconsin epidemiologic study of diabetic retinopathy. Arch Intern Med. 2004;164:1917-1924.

18. van Leiden HA, Dekker JM, Moll AC, et al. Risk factors for incident retinopathy in a diabetic and nondiabetic population: The Hoorn study. Arch Ophthalmol. 2003;121:245-251.

19. Wong TY, Klein R, Sharrett AR, et al. Retinal arteriolar diameter and risk for hypertension. Ann Intern Med. 2004;140:248-255.

20. Wong TY, Shankar A, Klein R, Klein BE, Hubbard LD. Prospective cohort study of retinal vessel diameters and risk of hypertension. BMJ. 2004;329:79.

21. Snead MP, Rubinstein MP, Jacobs PM. The optics of fundus examination. Surv Ophthalmol. 1992;36:439-445.

22. Lue TF. Erectile dysfunction. $N$ Engl J Med. 2000;342:1802-1813.

23. Shamloul R, Ghanem H, Abou-zeid A. Validity of the Arabic version of the sexual health inventory for men among Egyptians. Int J Impot Res. 2004;16:452-455.

24. Rosen RC, Cappelleri JC, Smith MD, Lipsky J, Pena BM. Development and evaluation of an abridged, 5-item version of the International Index of Erectile Function (IIEF-5) as a diagnostic tool for erectile dysfunction. Int J Impot Res. 1999;11:319-326.

25. Hyman BN. The eye as a target organ: An updated classification of hypertensive retinopathy. J Clin Hypertens (Greenwich). 2000;2:194-197.
26. Montorsi P, Montorsi F, Schulman CC. Is erectile dysfunction the "tip of the iceberg" of a systemic vascular disorder? Eur Urol. 2003;44:352-354.

27. Qureshi AI, Suri MF, Mohammad Y, Guterman LR, Hopkins LN. Isolated and borderline isolated systolic hypertension relative to long-term risk and type of stroke: A 20-year follow-up of the National Health and Nutrition Survey. Stroke. 2002;33:271-278.

28. Pearson TA. New tools for coronary risk assessment: What are their advantages and limitations? Circulation. 2002;105:886-892.

29. Stanton AV, Mullaney P, Mee F, O’Brien ET, O’Malley K. A method of quantifying retinal microvascular alterations associated with blood pressure and age. J Hypertens. 1995;13:41-48.

30. Chatterjee S, Chattopadhyay S, Hope-Ross M, Lip PL. Hypertension and the eye: Changing perspectives. J Hum Hypertens. 2002;16:667-675.

31. Dodson PM, Lip GY, Eames SM, Gibson JM, Beevers DG. Hypertensive retinopathy: A review of existing classification systems and a suggestion for a simplified grading system. J Hum Hypertens. 1996; 10:93-98.

32. Fuchs FD, Maestri MK, Bredemeier M, et al. Study of the usefulness of optic fundi examination of patients with hypertension in a clinical setting. J Hum Hypertens. 1995;9:547-551.

33. Schubert HD. Ocular manifestations of systemic hypertension. Curr Opin Ophthalmol. 1998;9:69-72.

34. Couper DJ, Klein R, Hubbard LD, et al. Reliability of retinal photography in the assessment of retinal microvascular characteristics: The Atherosclerosis Risk in Communities Study. Am J Ophthalmol. 2002;133:78-88

35. Grosso A, Veglio F, Porta M, Grignolo FM, Wong TY. Hypertensive retinopathy revisited: Some answers, more questions. Br JOphthalmol. 2005;89:1646-1654.
Clinical Ophthalmology

\section{Publish your work in this journal}

Clinical Ophthalmology is an international, peer-reviewed journal covering all subspecialties within ophthalmology. Key topics include: Optometry; Visual science; Pharmacology and drug therapy in eye diseases; Basic Sciences; Primary and Secondary eye care; Patien Safety and Quality of Care Improvements. This journal is indexed on

Submit your manuscript here: http://www.dovepress.com/clinical-ophthalmology-journal

\section{Dovepress}

PubMed Central and CAS, and is the official journal of The Society of Clinical Ophthalmology (SCO). The manuscript management system is completely online and includes a very quick and fair peer-review system, which is all easy to use. Visit http://www.dovepress.com/ testimonials.php to read real quotes from published authors. 